\title{
A high throughput passive dosing format for the Fish Embryo Acute Toxicity test
}

Vergauwen, Lucia; Nørgaard Schmidt, Stine; Stinckens, Evelyn; Maho, Walid; Blust, Ronny; Mayer, Philipp; Covaci, Adrian; Knapen, Dries

\section{Published in:}

Chemosphere

Link to article, DOI:

10.1016/j.chemosphere.2015.05.041

Publication date:

2015

Document Version

Publisher's PDF, also known as Version of record

Link back to DTU Orbit

Citation (APA):

Vergauwen, L., Nørgaard Schmidt, S., Stinckens, E., Maho, W., Blust, R., Mayer, P., Covaci, A., \& Knapen, D. (2015). A high throughput passive dosing format for the Fish Embryo Acute Toxicity test. Chemosphere, 139, 917. https://doi.org/10.1016/j.chemosphere.2015.05.041

\section{General rights}

Copyright and moral rights for the publications made accessible in the public portal are retained by the authors and/or other copyright owners and it is a condition of accessing publications that users recognise and abide by the legal requirements associated with these rights.

- Users may download and print one copy of any publication from the public portal for the purpose of private study or research.

- You may not further distribute the material or use it for any profit-making activity or commercial gain

- You may freely distribute the URL identifying the publication in the public portal 


\title{
A high throughput passive dosing format for the Fish Embryo Acute Toxicity test
}

\author{
Lucia Vergauwen $^{\mathrm{a}, *}$, Stine N. Schmidt ${ }^{\mathrm{b}}$, Evelyn Stinckens ${ }^{\mathrm{a}}$, Walid Maho ${ }^{\mathrm{c}}$, Ronny Blust ${ }^{\mathrm{d}}$, Philipp Mayer ${ }^{\mathrm{b}}$, \\ Adrian Covaci ${ }^{c}$, Dries Knapen ${ }^{a}$ \\ a Zebrafishlab, Veterinary Physiology and Biochemistry, Department of Veterinary Sciences, University of Antwerp, Universiteitsplein 1, 2610 Wilrijk, Belgium \\ ${ }^{\mathrm{b}}$ Department of Environmental Engineering, Technical University of Denmark, Miljoevej 113, 2800 Kgs. Lyngby, Denmark \\ ${ }^{\mathrm{c}}$ Toxicological Centre, Department of Pharmaceutical Sciences, University of Antwerp, Universiteitsplein 1, 2610 Wilrijk, Belgium \\ ${ }^{\mathrm{d}}$ Systemic Physiological and Ecotoxicological Research (SPHERE), Department of Biology, University of Antwerp, Groenenborgerlaan 171, 2020 Antwerpen, Belgium
}

\section{H I G H L I G H T S}

- Silicone O-rings are a practical means of applying passive dosing in the FET test.

- Controlled exposure conditions for phenanthrene were achieved.

-We report (sublethal) effect values in terms of chemical activity and body residue.

- Effect values were within ranges expected for baseline toxicity.

- Phenanthrene caused impaired swim bladder inflation and reduced motility.

\section{A R T I C L E I N F O}

\section{Article history:}

Received 11 February 2015

Received in revised form 8 May 2015

Accepted 12 May 2015

\section{Keywords:}

Phenanthrene

Polycyclic aromatic hydrocarbon

Zebrafish embryo

Fish early life stages

Acute toxicity

Critical body residue

\section{G R A P H I C A L A B S T R A C T}

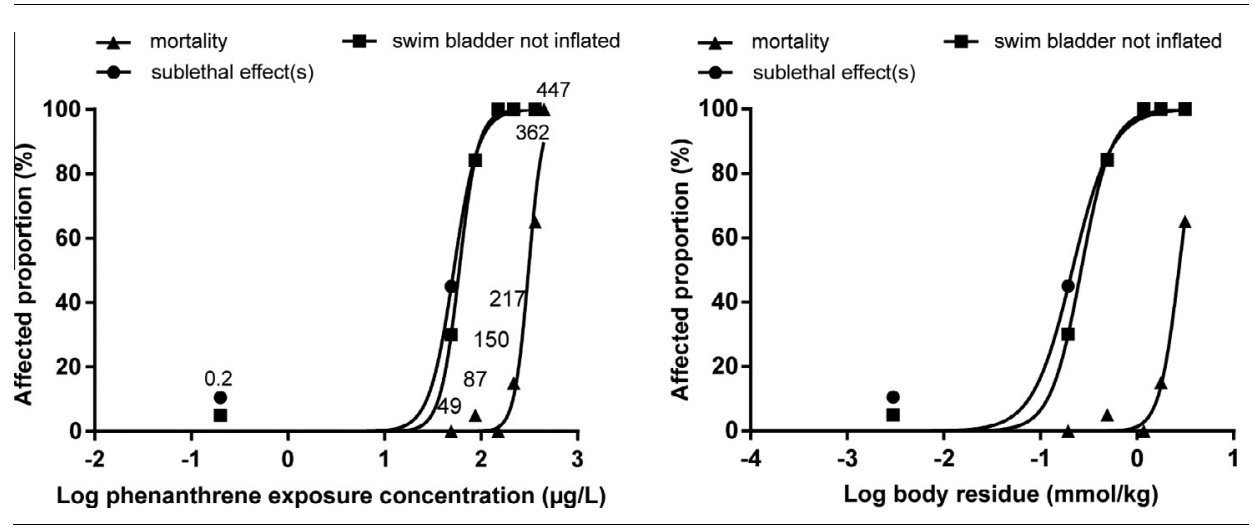

\begin{abstract}
A B S T R A C T
High throughput testing according to the Fish Embryo Acute Toxicity (FET) test (OECD Testing Guideline 236 ) is usually conducted in well plates. In the case of hydrophobic test substances, sorptive and evaporative losses often result in declining and poorly controlled exposure conditions. Therefore, our objective was to improve exposure conditions in FET tests by evaluating a passive dosing format using silicone O-rings in standard 24-well polystyrene plates. We exposed zebrafish embryos to a series of phenanthrene concentrations until $120 \mathrm{~h}$ post fertilization (hpf), and obtained a linear dilution series. We report effect values for both mortality and sublethal morphological effects based on (1) measured exposure concentrations, (2) (lipid normalized) body residues and (3) chemical activity. The $\mathrm{LC}_{50}$ for 120 hpf was $310 \mu \mathrm{g} / \mathrm{L}_{1} \mathrm{CBR}_{50}$ (critical body residue) was $2.72 \mathrm{mmol} / \mathrm{kg}$ fresh wt and La 50 (lethal chemical activity) was 0.047 . All values were within ranges expected for baseline toxicity. Impaired swim bladder inflation was the most pronounced morphological effect and swimming activity was reduced in all exposure concentrations. Further analysis showed that the effect on swimming activity was not attributed to impaired swim bladder inflation, but rather to baseline toxicity. We conclude that silicone O-rings (1) produce a linear dilution series of phenanthrene in the $120 \mathrm{hpf}$ FET test, (2) generate and maintain aqueous
\end{abstract}

Abbreviations: AhR, aryl hydrocarbon receptor; AOP, adverse outcome pathway; C, (regular) control; $\mathrm{CBR}_{(\mathrm{LIP}) 50}$, (lipid normalized) critical body residue; Ea ${ }_{50}$, effective

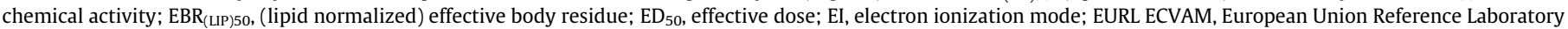

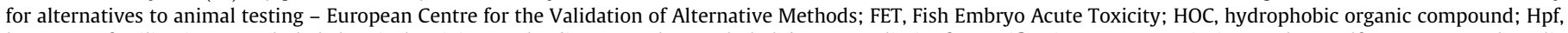

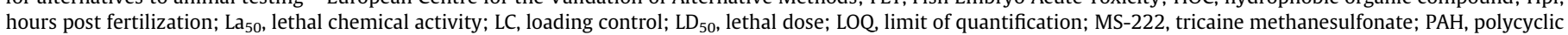
aromatic hydrocarbon; PDMS, polydimethylsiloxane; RC, O-ring control; SIM, selected ion monitoring; TG, Test Guideline.

* Corresponding author.

E-mail address: lucia.vergauwen@uantwerpen.be (L. Vergauwen). 
concentrations for reliable determination of effect concentrations, and allow for obtaining mechanistic toxicity information, and (3) cause no toxicity, demonstrating its potential as an extension of the FET test when testing hydrophobic chemicals.

(c) 2015 Elsevier Ltd. All rights reserved.

\section{Introduction}

The REACH legislation requires the collection of ecotoxicological information on chemicals, including aquatic toxicity information, while at the same time advocating reduced animal use. This has resulted in an increased attention for the development of alternative, non-animal test methods to assess chemical toxicity. In Europe, fish in general are non-protected animals until the stage of free-feeding (EU Directive 2010/63/EU). For zebrafish, this limit was set at $120 \mathrm{~h}$ post fertilization (hpf) when kept at approximately $28{ }^{\circ} \mathrm{C}$ (Commission Implementing Decision 2012/707/EU; Straehle et al., 2012). Therefore, the Fish Embryo Acute Toxicity (FET) test (OECD Test Guideline (TG) 236; OECD, 2013) up to $96 \mathrm{hpf}$ (or extended up to $120 \mathrm{hpf}$ ), which is specifically developed for zebrafish embryos, is considered an alternative testing method. In a validation study by EURL ECVAM (European Union Reference Laboratory for alternatives to animal testing - European Centre for the Validation of Alternative Methods) on behalf of the OECD, intra- and interlaboratory reproducibility of the FET test was assessed and found to be within acceptance criteria (Busquet et al., 2014). Additionally, Lammer et al. (2009) and Belanger et al. (2013) showed a high predictive capacity of the FET test for acute juvenile/adult fish toxicity. The FET test is the first ever accepted alternative for an animal testing method in ecotoxicology. However, a consensus about the predictive value of FET data for adult acute toxicity (as measured by e.g. OECD TG 203 (OECD, 1992)) for regulatory purposes has not yet been reached (Wim De Coen, ECHA, personal communication).

There is an ongoing international effort to further refine the FET test in terms of increasing its ability to inform on the mode of action (Hagenaars et al., 2014), as well as to solve practical issues such as dealing with poorly water-soluble chemicals (Butler et al., 2013; Seiler et al., 2014). Although the FET test performed well in the validation study by ECVAM, analytical measurement of the chemicals' concentration in the test medium showed important losses for some chemicals even though the medium was refreshed daily, probably due to sorption to the test chamber walls, volatilization and degradation (OECD, 2011, 2012a,b; Busquet et al., 2014). For the FET test, similar to other aquatic toxicity tests, hydrophobic organic compounds (HOCs) pose a challenge because of poorly controlled exposure conditions, and consequently poor estimation of toxicity.

Passive dosing is a method developed to overcome some of these challenges (Mayer et al., 1999). A polymer reservoir is loaded with the test chemical(s) and placed inside the test chamber during exposure. Continuous equilibrium partitioning of the test compound(s) between polymer and test medium ensures stable and controlled exposure concentrations, and the system thereby compensates loss processes. Also, the use of solvents, which can cause or modify toxicity, is avoided in this method.

Several passive dosing formats have recently been developed for different purposes. Smith et al. (2010a) used glass test vessels cast with a layer of PDMS as a passive dosing reservoir for exposure of Daphnia magna. Kramer et al. (2010) placed PDMS sheets on the bottoms of the wells of a 24-well plate, for exposure of fish cell lines that were grown on membranes of well plate inserts, and modelled free medium concentrations. Recently, two studies applied passive dosing for exposing zebrafish early life stages to HOCs. Butler et al. (2013) exposed zebrafish to three concentrations of phenanthrene, from fertilization up to 30 days. During the first 5 days, embryos were exposed individually in PDMS coated glass vials. After 5 days, surviving eleutheroembryos (developmental phase starting with hatching and ending with free-feeding) were transferred to a recirculating flow-through setup applying silicone O-rings. Seiler et al. (2014) tested the suitability of a passive dosing format for exposing zebrafish embryos to 10 polycyclic aromatic hydrocarbons (PAHs) until 48 hpf using glass jars with cast PDMS. They exposed 5-10 embryos in each glass jar and transferred them to plastic multi-well plates for microscopic observation at 24 and $48 \mathrm{hpf}$. Applying passive dosing in standard polystyrene 24 -well plates, which are routinely used in the FET test, would combine the advantages of the passive dosing method with easy individual microscopic follow-up and high throughput. This would also allow for the application of individual automated behaviour analysis directly in the well plates. By combining these measurements with measures of growth, morphology and body residue, vital mechanistic toxicity information can be obtained. Smith et al. (2010b) developed a suitable passive dosing format for use in polystyrene 24-well plates in in vitro toxicity tests. Silicone O-rings proved to be practical and showed excellent equilibrium partitioning characteristics for HOCs with $\log K_{\mathrm{ow}} \geqslant 3$. In this study, we used this methodology for exposing zebrafish embryos up to $120 \mathrm{hpf}$ to a HOC in standard 24-well plates. We used phenanthrene $\left(\log K_{\text {ow }}: 4.46\right)$ as a model compound, and loaded silicone $\mathrm{O}$-rings by equilibrium partitioning from a phenanthrene dilution series in methanol.

In summary, our objective was to evaluate passive dosing with silicone O-rings for use in a $120 \mathrm{hpf}$ FET test. We wanted to assess whether (1) silicone O-rings are able to produce a linear dilution series of phenanthrene in the 120 hpf FET test, (2) whether controlled exposure concentrations facilitate precise determination of effect concentrations, and allow for obtaining mechanistic toxicity information, and (3) whether the passive dosing format itself causes toxicity in the zebrafish embryos.

\section{Material and methods}

\subsection{Experimental design}

Zebrafish embryos were exposed in a 120 hpf FET test to six phenanthrene concentrations (Table 1) using silicone O-rings (outer diameter: $14.4 \mathrm{~mm}$; cross section: $2.4 \mathrm{~mm}$; average weight: $0.22 \mathrm{~g}$; product no. ORS-0096-24, Altec, Cornwall, UK). Additionally, losses from a conventionally spiked medium without O-rings were assessed. A series of controls was used to assess potential effects of the O-rings: a regular reconstituted freshwater control without O-rings (control, C), a control with O-ring that was not subjected to the loading procedure (O-ring control, RC), and a control with O-ring that was subjected to the loading procedure with clean methanol (loading control, LC). For each of the ten conditions (Table 1), one 24-well plate was used. 20 wells were used to test each respective condition (i.e. 20 embryos per condition) and four wells were used as internal negative control (reconstituted freshwater). One 48-well plate contained four concentrations of 
Table 1

Experimental conditions of the 120 hpf FET test with their respective estimated and measured medium concentrations and body residues.

\begin{tabular}{|c|c|c|c|c|c|}
\hline $\begin{array}{l}\text { Experimental } \\
\text { condition }\end{array}$ & $\begin{array}{l}\text { Estimated phenanthrene } \\
\text { concentration }^{\mathrm{a}}(\mu \mathrm{g} / \mathrm{L})\end{array}$ & $\begin{array}{l}\text { Phenanthrene exposure } \\
\left.\text { concentration (avg } \pm \mathrm{SD}^{\mathrm{b}} \mu \mathrm{g} / \mathrm{L}\right)\end{array}$ & $\begin{array}{l}\% \text { of estimated } \\
\text { concentration } \\
\left(\operatorname{avg} \pm \mathrm{SD}^{\mathrm{b}}\right)\end{array}$ & $\begin{array}{l}\text { Accumulated phenanthrene } \\
\text { dose (avg } \pm \mathrm{SD}^{\mathrm{C}} \text { ng/embryo) }\end{array}$ & $\begin{array}{l}\text { Body residue } \\
\left(\operatorname{avg} \pm \mathrm{SD}^{\mathrm{C}} \mathrm{mmol} / \mathrm{kg}\right)\end{array}$ \\
\hline Control (C) & 0 & $\leqslant 0.2$ & - & $\leqslant 0.2$ & $\leqslant 0.003$ \\
\hline Ring control (RC) & 0 & $\leqslant 0.2$ & - & $\leqslant 0.2$ & $\leqslant 0.003$ \\
\hline $\begin{array}{l}\text { Loading control } \\
\text { (LC) }\end{array}$ & 0 & $\leqslant 0.2$ & - & $\leqslant 0.2$ & $\leqslant 0.003$ \\
\hline Concentration 1 & 98 & $49 \pm 9$ & $49 \pm 9$ & $15 \pm 7$ & $0.19 \pm 0.09$ \\
\hline Concentration 2 & 157 & $87 \pm 13$ & $56 \pm 8$ & $38 \pm 10$ & $0.49 \pm 0.17$ \\
\hline Concentration 3 & 251 & $150 \pm 22$ & $60 \pm 9$ & $85 \pm 49$ & $1.18 \pm 0.69$ \\
\hline Concentration 4 & 402 & $217 \pm 35$ & $54 \pm 9$ & $130 \pm 55$ & $1.78 \pm 0.78$ \\
\hline Concentration 5 & 644 & $362 \pm 43$ & $56 \pm 7$ & $188^{\mathrm{e}}$ & $3.15^{\mathrm{e}}$ \\
\hline Concentration 6 & 1030 & $447 \pm 13^{\mathrm{d}}$ & $43^{\mathrm{d}} \pm 1$ & $-{ }^{f}$ & $-{ }^{f}$ \\
\hline $\begin{array}{l}\text { Spiked } \\
\quad \text { concentration }\end{array}$ & 200 & $100 \pm 99$ & $50 \pm 50$ & $5 \pm 1$ & $0.059 \pm 0.014$ \\
\hline
\end{tabular}

${ }^{a}$ Estimated concentrations were corrected for the temperature difference between loading and exposure (see Appendix).

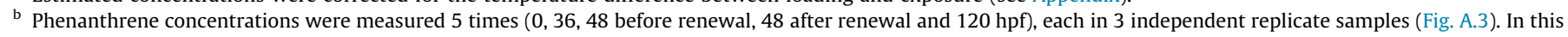
table, values are shown as average \pm SD of all measurements (Fig. 1).

c Values are shown as average \pm SD of four independent biological replicates, each containing 4 or 5 eleutheroembryos.

d In concentration 6, all embryos were dead at $24 \mathrm{hpf}$ and therefore the medium concentration was only measured at 0 hpf.

e In concentration 5, only 7 embryos survived, resulting in only one sample and no SD.

${ }^{f}$ In concentration 6 , none of the embryos survived and therefore the body residue could not be determined.

3,4-dichloroaniline (CAS 95-76-1, purity of 98\%, Sigma-Aldrich, Saint Louis, US), 0.5, 1, 2 and $4 \mathrm{mg} / \mathrm{L}$ as positive control (OECD, 2013).

\subsection{Passive dosing}

After an initial cleaning, silicone O-rings were loaded from methanol solutions by equilibrium partitioning (Smith et al., 2010a). Loading from a saturated methanol solution results in saturation of the silicone and subsequently saturation of the test medium during exposure. Additionally, loading from dilutions of the saturated methanol solution results in corresponding dilutions of the test medium proportional to the maximum soluble concentration. However, this only holds true when loading and exposure are performed at the same temperature. A saturated methanol solution at $28.5^{\circ} \mathrm{C}$ immediately precipitates when the temperature drops even slightly, for example due to handling with a pipette. Therefore, loading was carried out at room temperature $\left(20^{\circ} \mathrm{C}\right)$ while equilibration and exposure were performed at $28.5^{\circ} \mathrm{C}$. Estimated concentrations are needed as a reference for assessing the actual exposure concentrations in the test, and were calculated applying a temperature correction. O-rings were equilibrated with reconstituted freshwater for $40 \mathrm{~h}$ prior to the start of the exposure (see Appendix for more details on the passive dosing method and calculations).

\subsection{Preparation of spiked phenanthrene exposure}

The appropriate quantity of phenanthrene was dissolved in medium through sonication. The test wells were pre-equilibrated with $2 \mathrm{~mL}$ of the test solution at $28.5^{\circ} \mathrm{C} 24 \mathrm{~h}$ prior to the start of the exposure. Immediately prior to the start of the exposure, the test solution in the wells was replaced.

\subsection{Experimental procedure}

\subsubsection{Collection of eggs and exposure}

Non-exposed adult wildtype zebrafish (Danio rerio) were maintained and used for egg production (Appendix). Reconstituted freshwater $\left(45 \mathrm{mg} / \mathrm{L} \mathrm{CaCO}_{3}\right)$ was prepared by adding Instant Ocean $^{\circledR}$ Sea Salt (Blacksburg, VA, US) to reverse osmosis water (Werner, Leverkusen, Germany) up to a conductivity of
$500 \mu \mathrm{S} / \mathrm{cm}$ and adjusting the $\mathrm{pH}$ to 7.5 using $\mathrm{NaHCO}_{3}$, and was used to prepare all test solutions as well as to keep adult fish. Embryos were transferred to exposure plates within $2 \mathrm{hpf}$ and placed in an incubator at $28.5^{\circ} \mathrm{C}$ with a $14 \mathrm{~h} / 10 \mathrm{~h}$ light/dark cycle. Mortality, using the four endpoints described in OECD TG 236 (OECD, 2013), and hatching were recorded every $24 \mathrm{~h}$, by observing the embryos directly in the wells using a S8APO stereomicroscope (Leica Microsystems GmbH, Germany), and the chorion was removed from the test chamber after hatching.

Exposure medium and O-rings in all treatments were replaced at $72 \mathrm{hpf}$, in order to maintain adequate water quality and because preliminary experiments showed depletion of the O-rings after $120 \mathrm{~h}$. The spiked phenanthrene solution, as well as the DCA positive control solution, were replaced every $48 \mathrm{~h}$.

\subsubsection{Sublethal effect assessment}

2.4.2.1. Automated swimming behaviour analysis. At $120 \mathrm{hpf}$, the swimming activity of all eleutheroembryos was determined in the 24-well plates using a Zebrabox 3.0 video tracking device (ViewPoint, Lyon, France). One hour before analysis, O-rings were removed because they interfere with image detection. Additionally, eleutheroembryos were allowed to acclimate for $20 \mathrm{~min}$ to the Zebrabox environment before analysis. Data were analysed using the ZebraLab software version 3.20.5.104. The path of each eleutheroembryo was analysed and the total distance travelled (further referred to as swimming movements) was calculated. The sum of all swimming movements (in $\mathrm{mm}$ ) in $30 \mathrm{~min}$ was compared among conditions. Additionally, the proportion of the movements at different swim speeds ( 3 categories: $\leqslant 2 \mathrm{~mm} / \mathrm{s}$, $2-10 \mathrm{~mm} / \mathrm{s}, \geqslant 10 \mathrm{~mm} / \mathrm{s}$ ) was compared.

2.4.2.2. Morphological scoring. After the behaviour analysis, eleutheroembryos were anaesthetised using $100 \mathrm{mg} / \mathrm{L}$ MS-222 (tricaine methanesulfonate, Sigma-Aldrich) adjusted to $\mathrm{pH} 7.5$ using $\mathrm{NaHCO}_{3}$ and morphological abnormalities were scored, including failure to hatch, impaired swim bladder inflation (posterior chamber), tail malformations (curvature, elbow, tissue deviation), oedemas (pericardium, yolk), blood accumulations (heart, yolk (extension), swim bladder), absent blood circulation in the tail, malformations of fins (absence, curved), yolk, mouth, eyes and otoliths. Eleutheroembryos were photographed together with a calibrator, using a camera (Canon EOS 600D, 18 megapixel) mounted 
on the stereomicroscope, and images were analysed using the Image J software (http://rsbweb.nih.gov/ij/) to determine standard length $( \pm 0.002 \mathrm{~mm})$.

\subsection{Analytical measurements}

Medium samples were taken at $0 \mathrm{hpf}$ (after equilibration), $36 \mathrm{hpf}, 72 \mathrm{hpf}$ (both before and after O-ring and medium renewal) and $120 \mathrm{hpf}$. At each time point, 3 independent replicate samples were taken from each condition. In each sample, $100 \mu \mathrm{L}$ from 6 distinct wells was combined ( $600 \mu \mathrm{L}$ total). From the spiked medium, samples were taken at $0 \mathrm{hpf}$ (after renewal), $48 \mathrm{hpf}$ (both before and after renewal), $96 \mathrm{hpf}$ (both before and after renewal) and 120 hpf. Samples were only taken from wells where embryos were alive. Samples were stored in Gas Chromatography (GC) vials (5182-0716, Agilent Technologies, Palo Alto, CA, USA) at $-20^{\circ} \mathrm{C}$ until GC-MS analysis.

After the sublethal effect assessment at $120 \mathrm{hpf}$, eleutheroembryos were euthanized using an overdose of $1 \mathrm{~g} / \mathrm{L}$ MS-222 adjusted to $\mathrm{pH} 7.5$, transferred to a nylon $100 \mu \mathrm{m}$ filter (BD Biosciences, Durham, NC, USA), rinsed with reconstituted freshwater, transferred to $30 \mathrm{~mL}$ of clean reconstituted freshwater twice, and finally transferred to GC vials. For each sample, 4 or 5 eleutheroembryos from the same condition were pooled. The extracts were analysed using an Agilent Technologies 6890 gas chromatograph coupled to an Agilent 5973 mass spectrometer operated in electron ionization mode (EI). For more details, see Appendix.

\subsection{Calculations}

Effective chemical activities were determined as the ratio of $\mathrm{LC}_{50}$ or $\mathrm{EC}_{50}$ and the subcooled liquid solubility of phenanthrene (Mayer and Reichenberg, 2006) (Appendix). For calculation of critical (mortality) and effective (sublethal effect) body residue $\left(\mathrm{CBR}_{50}\right.$ and $\mathrm{EBR}_{50}$ ), final eleutheroembryo weight was calculated based on dimensions measured in photographs, using imageJ (Appendix). Based on the body residues, the bioconcentration factor (BCF) was calculated as the ratio of the body residue at $120 \mathrm{hpf}(\mu \mathrm{g} / \mathrm{kg}$ fresh wt) and the average measured medium concentration $(\mu \mathrm{g} / \mathrm{L})$. Total lipid content was determined in 5 samples (of 25 , $120 \mathrm{hpf}$ non-exposed eleutheroembryos) according to methods previously described (Vergauwen et al., 2013), and used to calculate the lipid normalized critical body residue $\left(\mathrm{CBR}_{\mathrm{LIP50}}\right)$ as the ratio of the body residue $(\mathrm{mmol} / \mathrm{kg}$ fresh $\mathrm{wt}$ ) and the lipid content $(\mathrm{w} / \mathrm{w}$, fresh wt).

\subsection{Statistical analysis}

Treatments with O-rings that were loaded with methanol (LC) served as controls and reference for the calculation of the various toxicity endpoints. Data were considered significantly different when $p$-values were $<0.05$. Linear regression was used to (1) compare measured to estimated exposure concentrations, (2) relate body residues to exposure concentrations, and (3) relate length to body residue. Proportions of mortality, impaired swim bladder inflation and other sublethal morphological effects were analysed as a function of exposure concentration and body residues using a nonlinear regression estimate (variable hill slope, top and bottom constrained at 100 and 0 ), and effect values were calculated. Additionally, the frequency data for morphological abnormalities were compared among conditions using a chi-squared contingency table test, with a Bonferroni post hoc test to adjust for multiple testing. Standard length, total swimming movements and proportions of swimming movements at specific swim speeds were not normally distributed (Shapiro-Wilk normality test), and to determine significant effects, Kruskal-Wallis tests with Dunn's multiple comparison tests were used. All statistical analyses were performed in GraphPad Prism Version 6.00 for Windows (GraphPad Software, La Jolla California, USA).

\section{Results and discussion}

In this study, we evaluated a passive dosing format, facilitating controlled exposure to hydrophobic chemicals in a FET test (OECD, 2013). The FET test was extended up to $120 \mathrm{hpf}$, which is consistent with the definition of non-protected animals (Straehle et al., 2012). We critically examined three requirements such a passive dosing format should meet, corresponding to our study objectives.

\subsection{Requirement 1: Linearity and goodness of fit of exposure concentration series}

Fig. 1 shows a linear relation between the estimated and measured phenanthrene concentrations in the medium $\left(R^{2}=0.945\right.$; Table 1, and Fig. A.3 in Appendix, show the medium concentrations in more detail). Measured concentrations were on average $55 \%$ of estimated concentrations and ranged from $49 \%$ to $60 \%$ with standard deviations of $7 \%$ to $9 \%$ (calculated over all replicates from all time points for each condition) of estimated concentrations during the 5 day exposure. Phenanthrene was not detected in control media (Table 1 ).

In the conventionally spiked condition without O-rings (Fig. A.3), medium concentrations dropped from $200 \mu \mathrm{g} / \mathrm{L}$ to $1-2 \mu \mathrm{g} / \mathrm{L}$ within $24 \mathrm{~h}$ (from 96 to $120 \mathrm{hpf}$ ). Riedl and Altenburger (2007) showed that for substances with $\log K_{\mathrm{ow}}>3$, assays in polystyrene multi-well plates underestimate toxicity due to losses. The FET testing guideline mentions that in case adsorption to polystyrene is suspected, inert materials (glass) should be used to reduce losses (OECD, 2013). However, Schreiber et al. (2008) showed that even the use of glass multi-well plates still resulted in a $40 \%$ loss of phenanthrene after $48 \mathrm{~h}$. This confirms the need for passive dosing of HOCs, and our results show that polystyrene plates can be used when passive dosing is applied.

Two studies have previously reported the use of passive dosing for zebrafish embryo/larval exposure to PAHs. Butler et al. (2013) used a combination of silicone coated vials and silicone O-rings in a flow-through system to chronically expose zebrafish embryos/larvae to phenanthrene and exposure concentrations were $86-104 \%$ of estimated concentrations with standard deviations of $10-14 \%$. Recently, Seiler et al. (2014) reported exposure concentrations of $60-117 \%$ of estimated concentrations and

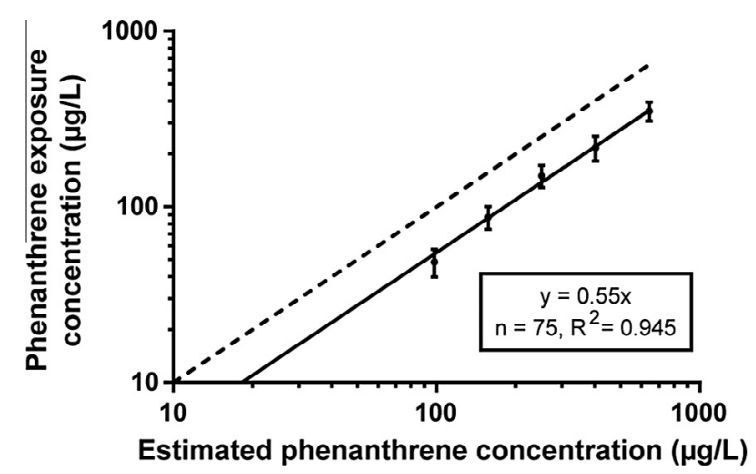

Fig. 1. Overview of exposure concentrations in the 120 hpf FET test using passive dosing. The highest concentration $(447 \mu \mathrm{g} / \mathrm{L})$ was not included, since this concentration was only measured at the beginning of the test (all embryos died within $24 \mathrm{~h}$ ). The full line represents a linear regression fit based on all measurements $(p<0.001)$. A 1:1 relation is included as a visual reference (dotted line). Logarithmic axes are used (average \pm SD of all measurements, Table 1 ). 
standard deviations ranging from $0 \%$ to $23 \%$ when exposing zebrafish embryos to 10 PAHs in silicone cast $60 \mathrm{~mL}$ jars. Several factors possibly contributed to the deviation from estimated exposure concentrations in our study: Firstly, it is important to be aware that the estimation of exposure concentrations based on partition coefficients is associated with some error. Secondly, the use of polystyrene plates instead of glass, the use of small exposure volumes resulting in a higher surface/volume ratio and therefore more sorption, and not stirring the medium during exposure may have reduced exposure concentrations. However, these are exactly the factors that make the passive dosing format necessary and compatible with the existing FET test guideline (OECD, 2013), and we have shown that even under these circumstances we can produce a linear dilution series with a high goodness of fit. Therefore, we can conclude that the proposed passive dosing format, using silicone O-rings, is a valuable addition to the routinely applied FET test (OECD, 2013) when testing hydrophobic chemicals, provided that analytical measurements of the exposure medium are performed and used as final exposure concentrations to interpret toxicity observations. We suggest the following further improvements to the method: Firstly, the use of glass 24-well plates could reduce sorption and therefore avoid the need to replace the rings after $72 \mathrm{~h}$. Secondly, equilibrating O-rings with medium in glass bottles overnight on a shaker before transferring to the well plates could increase the exposure concentrations.

\subsection{Requirement 2: Precise determination of effect concentrations, offering mechanistic toxicity information}

\subsubsection{Impaired swim bladder inflation was the most pronounced morphological effect}

At the four lowest exposure concentrations, the only significant sublethal morphological effect was impaired inflation of the posterior chamber of the swim bladder (Figs. 2 and $3 \mathrm{~A}$ ). Since the test was ended at $120 \mathrm{hpf}$, we could not discriminate between a complete lack of swim bladder inflation and delayed swim bladder inflation. Incardona et al. (2004) also reported that different PAHs, including phenanthrene, caused delayed or failed inflation of the swim bladder. PAHs have multiple modes of action in the aquatic environment, including AhR (aryl hydrocarbon receptor) mediated and AhR-independent (cardio)toxicity and narcosis (Di Toro et al., 2000; Billiard et al., 2006). Phenanthrene in particular has been demonstrated to have low AhR binding affinity, to have a resulting inability to induce CYP1a, to cause cardiotoxicity through AhR independent pathways, and to act as a non-polar narcotic (baseline toxicant), implying that it disrupts membranes due to its lipophilic nature (Hawkins et al., 2002; Barata et al., 2005; Incardona et al., 2005). Villeneuve et al. (2014) used the adverse outcome pathway (AOP) framework to hypothesize possible mechanisms underlying impaired swim bladder inflation. Recent research has shown that compounds from a wide variety of chemical classes and modes of action impair swim bladder inflation (Hagenaars et al., 2014; Lanham et al., 2014; Wang et al., 2014), probably through a variety of underlying mechanisms (e.g., Bagci et al., 2015). However, the current description of AOPs related to swim bladder inflation do not provide information to understand the role of narcosis, and AOPs related to narcosis do not specifically focus on swim bladder inflation effects. The link between these two has therefore yet to be established. Such integrated AOP assessments involving different mechanisms and pathways require an AOP network approach, a concept that is still under development (Knapen et al., 2015).

In the second highest exposure concentration $(362 \mu \mathrm{g} / \mathrm{L})$, mortality was $65 \%, 43 \%$ of survivors were not hatched at $120 \mathrm{hpf}$ $(n=3)$, and all hatched eleutheroembryos $(n=4)$ had uninflated swim bladders and tail malformations (curvature, elbow and/or tissue deviation). Furthermore, surviving embryos $(n=7)$ were severely malformed with $71 \%$ oedemas (pericardium and/or yolk), $57 \%$ blood accumulations (in the heart, in the yolk (extension) and/or adjacent to the swim bladder), 57\% absent blood circulation in the tail, $43 \%$ fin malformations (one or both fins absent or curved), $43 \%$ yolk malformations and $57 \%$ mouth malformations (Fig. 2). These proportions were all significantly different from LC. These observations correspond to what Incardona et al. (2004) termed a characteristic suite of abnormalities in teleost embryos exposed to petroleum-derived $\mathrm{PAH}$ mixtures, including cardiac dysfunction, pericardial and yolk sac oedema, reduced size of the jaw and curvature of the tail. Butler et al. (2013) found similar phenotypes of $120 \mathrm{hpf}$ zebrafish eleutheroembryos exposed to phenanthrene, with oedemas of pericardium and yolk, as well as curvatures of the tail.

\subsubsection{Phenanthrene was lethal during the first $24 \mathrm{~h}$ of exposure}

All mortalities were already observed at $24 \mathrm{hpf}$, except for one embryo in the $217 \mu \mathrm{g} / \mathrm{L}$ exposure that had not hatched and died at $120 \mathrm{hpf}$. Firstly, we can conclude that embryos were already able to take up phenanthrene through the chorion, which was also shown by Petersen and Kristensen (1998). Secondly, LC 50 values at $96 \mathrm{hpf}$ and $120 \mathrm{hpf}$ can be considered identical (Table 2). Our calculated $\mathrm{LC}_{50}$ of $310.0 \mu \mathrm{g} / \mathrm{L}$ was in the range of previously reported $96 \mathrm{~h} \mathrm{LC} 50$ values of 234 and $375 \mu \mathrm{g} / \mathrm{L}$ for juvenile Lepomis macrochirus and Salmo gairdneri respectively (Call et al., 1986), and slightly lower than the 7 day LC $_{50}$ for zebrafish reported by Petersen (1997) of $536 \mu \mathrm{g} / \mathrm{L}$, and the TLM (target lipid model for toxicity assessment of residual petroleum constituents) predicted $96 \mathrm{~h} \mathrm{LC}_{50}$ for zebrafish of $510 \mu \mathrm{g} / \mathrm{L}$ (McGrath and Di Toro, 2009).

\subsubsection{Effect values were within ranges expected for baseline toxicity}

Some generalizations have been proposed with regard to baseline toxicity. Firstly, baseline toxicity is assumed to initiate in the chemical activity range of $0.01-0.1$, which corresponds to $1-10 \%$ of (subcooled) liquid solubility (Reichenberg and Mayer, 2006; Schmidt and Mayer, 2015). We report an $\mathrm{La}_{50}$ of 0.047 , which is in this range (for detailed calculations, see Appendix). Ea 50 values of 0.009 and 0.008 for impaired swim bladder inflation and any sublethal morphological effect respectively, are slightly below the range, as expected.

The second assumption uses critical body residues to compare toxicities among chemicals and test species, because they are a more direct measure of toxicity than indirect metrics such as $\mathrm{LC}_{50}$, which are based on exposure media concentrations and influenced by bioavailability, uptake, biotransformation, etc. (Mackay et al., 2014). The $\log$ BCF was $3.02 \pm 0.21 \mathrm{~L} / \mathrm{kg}$ fresh wt (average \pm SD over all samples). Although we did not verify that steady-state was reached in the larvae, Petersen and Kristensen (1998) showed that steady-state conditions for phenanthrene were already reached after $20 \mathrm{~h}$ in zebrafish larvae at the end of the yolk sac stage (presumably around $7 \mathrm{dpf}$ ), and hypothesized that this was due to the small size of the larvae and thus an increased total surface of the membranes per unit fish weight compared to juveniles/adults. Furthermore, our value was in very good agreement with the experimentally determined $\log$ BCF of $3.20 \mathrm{~L} / \mathrm{kg}$ fresh wt (assuming an $80 \%$ water content for conversion from dry weight to fresh weight) reported by Petersen and Kristensen (1998). CBRs are expected to be similar (in the range of $2-8 \mathrm{mmol} / \mathrm{kg}$ ) among baseline toxicants and small aquatic organisms due to similar mode of action (Van Wezel and Opperhuizen, 1995). Recently, van der Heijden et al. (2015) showed that CBR values for seven narcotics tested in three species ranged from 2.1 to $16.1 \mathrm{mmol} / \mathrm{kg}$ fresh wt. McCarty et al. (2013) reviewed a large set of CBR values and reported a mean CBR of $1.80 \mathrm{mmol} / \mathrm{kg}$ fresh wt for 29 narcotics in algae, invertebrates and fish. CBR values for phenanthrene in 


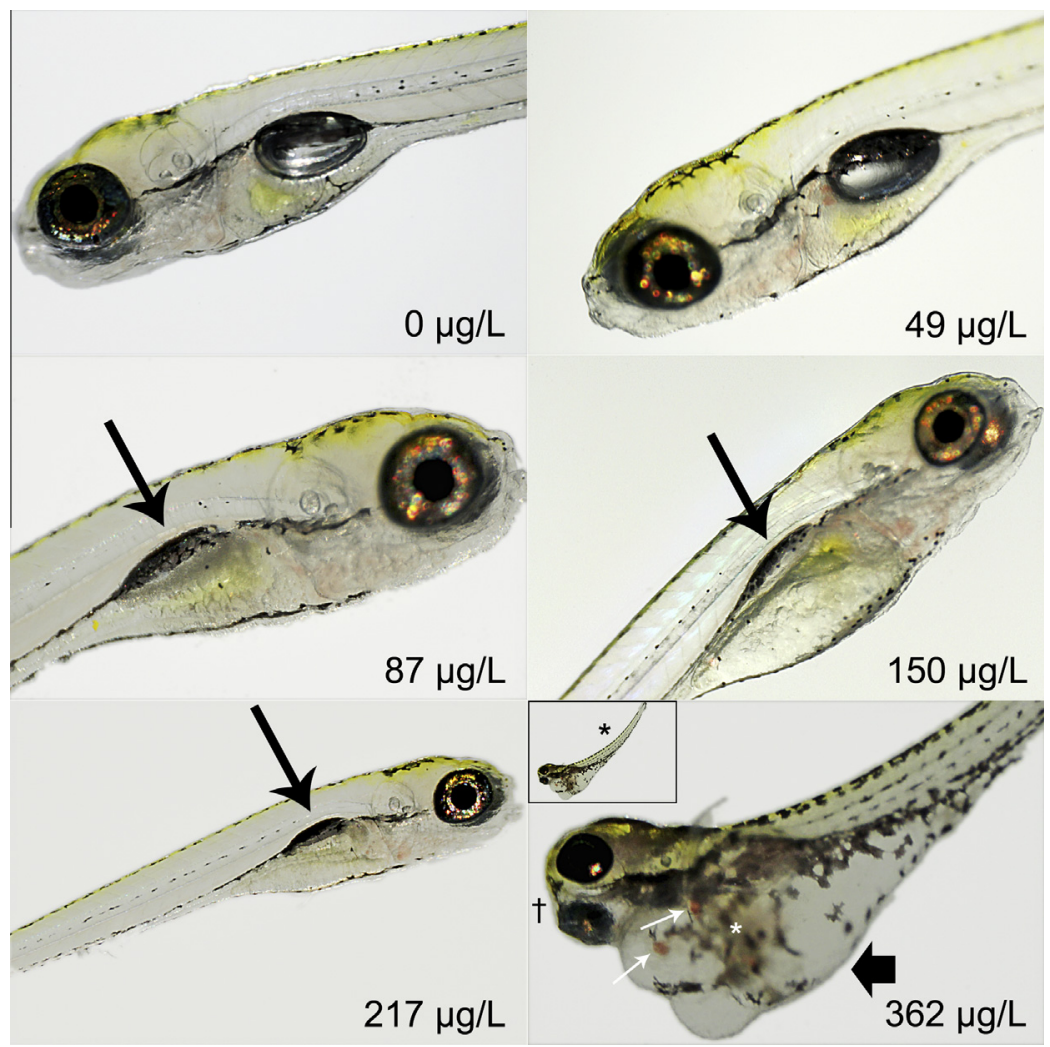

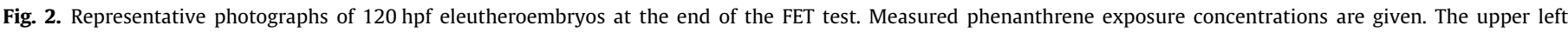

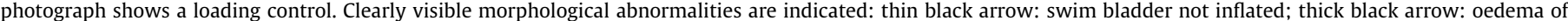

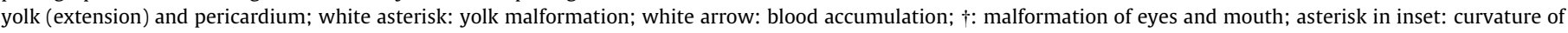
the tail.

invertebrates ranged from 0.32 to $8.40 \mathrm{mmol} / \mathrm{kg}$ (McCarty et al., 2013). Our CBR value of $2.72 \mathrm{mmol} / \mathrm{kg}$ fresh wt fits very well into this range (Table 2). Furthermore, our critical and effective body residues (Table 2) are in the same range as the CBR and EBR (E: bent chorda) values of 3.48 and $0.80 \mathrm{mmol} / \mathrm{kg}$ fresh wt reported by Petersen (1997) after exposure of zebrafish larvae to phenanthrene.

Thirdly, lipid normalized CBRs are expected to be similar among baseline toxicants and small aquatic organisms due to similarity at target site (cell membranes containing phospholipids). The lipid content of $120 \mathrm{hpf}$ unexposed zebrafish was $1.63 \% \pm 0.29 \%$ (SD) (w/w, fresh wt), and our $\mathrm{CBR}_{\text {LIP50 }}$ of $167 \mathrm{mmol} / \mathrm{kg}$ lipids was very close to the expected range of $40-160 \mathrm{mmol} / \mathrm{kg}$ (Van Wezel and Opperhuizen, 1995), but was higher than the mean CBR $_{\text {LIP50 }}$ of $53.9 \mathrm{mmol} / \mathrm{kg}$ lipid reported for 29 narcotics in algae, invertebrates and fish (McCarty et al., 2013). Our observation that the CBR fits nicely into the expected interval while the lipid normalized CBR is rather high relative to what is expected, may be due to the fact that lipid corrected CBR values are subject to variation in both lipid content and composition, which may compromise their accuracy (McCarty et al., 2013). For sublethal effects we report EBR $_{\text {LIP50 }}$ (swim bladder): $16 \mathrm{mmol} / \mathrm{kg}$ lipids and EBR $_{\text {LIP50 }}$ (sublethal effects): $13 \mathrm{mmol} / \mathrm{kg}$ lipids, which are below the range, as expected.

In this way, our results support that phenanthrene exerted baseline toxicity. They also support the findings of Belanger et al. (2013) who showed that the FET test has good predictability for in vivo effects in fish, also for highly hydrophobic compounds $\left(\log K_{\mathrm{ow}}>3\right)$. Currently, generalized assumptions about narcosis are limited to mortality. Through the application of the same concepts for calculating and comparing sublethal effect values among chemicals and species, our understanding of the narcosis mechanism can be greatly improved.
3.2.4. Reduced swimming activity was attributed to baseline toxicity

We observed reduced swimming activity in all phenanthrene exposure concentrations compared to LC (Fig. 4A). This was caused by an altered activity pattern as shown in Fig. 4C. Exposed eleutheroembryos made fewer movements at swim speeds higher than $10 \mathrm{~mm} / \mathrm{s}$ compared to LC. Furthermore, they made significantly more swimming movements at swim speeds lower than $2 \mathrm{~mm} / \mathrm{s}$, and at $217 \mu \mathrm{g} / \mathrm{L}$ they additionally made fewer movements at swim speeds between 2 and $10 \mathrm{~mm} / \mathrm{s}$. This shows that exposed eleutheroembryos were able to reach high swim speeds, but were less active. One could expect that this reduced swimming activity is caused by the failure to inflate the swim bladder. However, for the lowest exposure concentration, we were able to compare eleutheroembryos with and without inflated swim bladders and we found no difference (Fig. 4B and D). On the one hand, it is possible that the function of the swim bladder was impaired even in those cases where the swim bladder was inflated. On the other hand, narcosis is commonly associated with reduced motility due to decreased respiratory-cardiovascular functions, and with altered energy metabolism which can indirectly influence motility and affect growth (McKim et al., 1987). Barata et al. (2005) also showed decreased motility after exposure of the copepod Oithona davisae to phenanthrene. When standard length was compared among all exposure conditions, we found that growth was reduced in eleutheroembryos exposed to $362 \mu \mathrm{g} / \mathrm{L}$ (Fig. 3E), and linear regression analysis showed that length proportionately decreased with increasing body residue (Fig. 3F). This may indicate that energy was diverted from growth to detoxification and homeostasis, in line with the metabolic cost hypothesis (Rowe et al., 2001).

While previous studies were able to investigate the nature of effects of hydrophobic compounds, they were mostly not able to link these effects to stable exposure concentrations in order to establish 


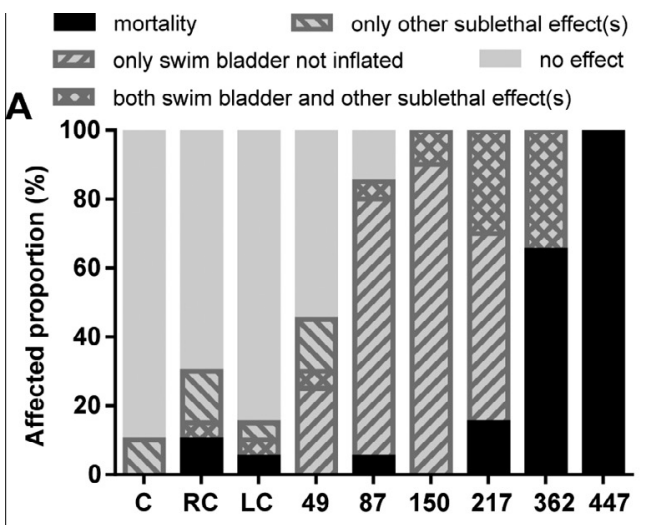

Phenanthrene exposure concentration ( $\mu \mathrm{g} / \mathrm{L})$
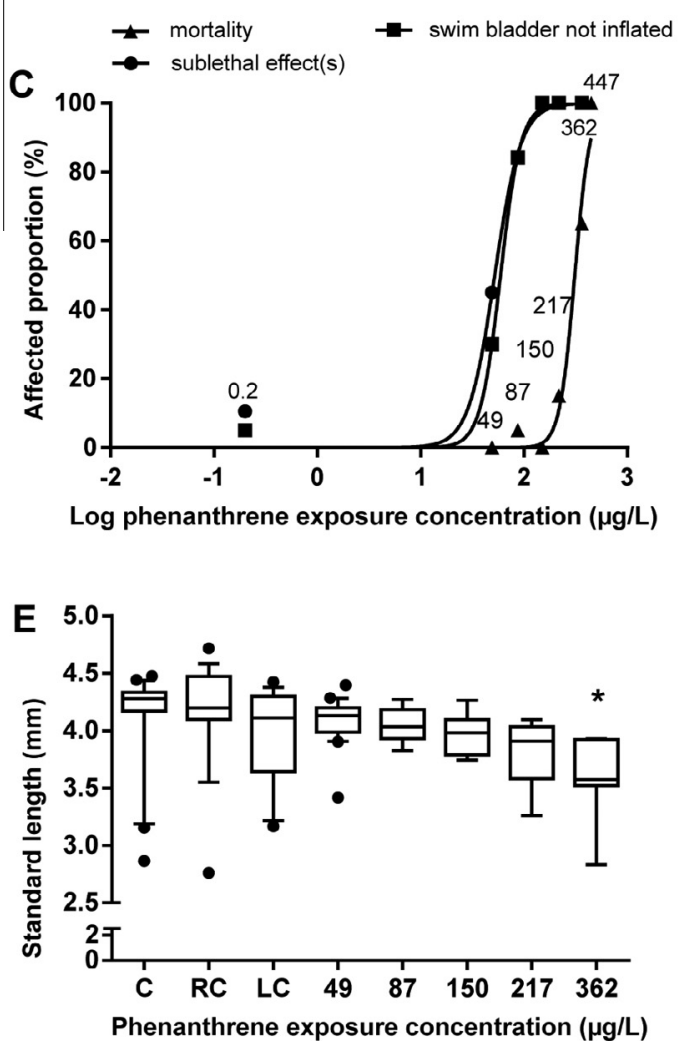

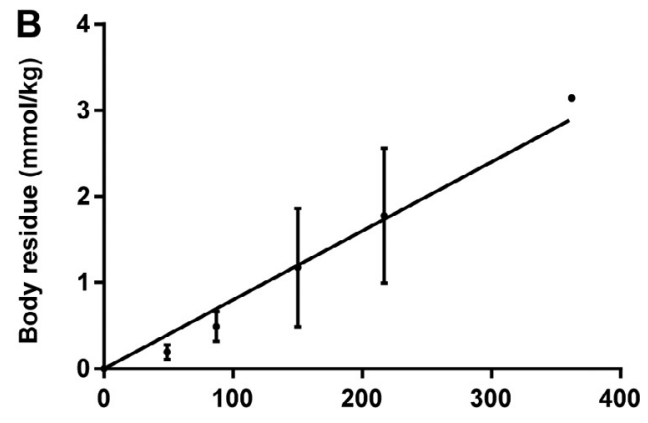

Phenanthrene exposure concentration ( $\mu \mathrm{g} / \mathrm{L}$ )
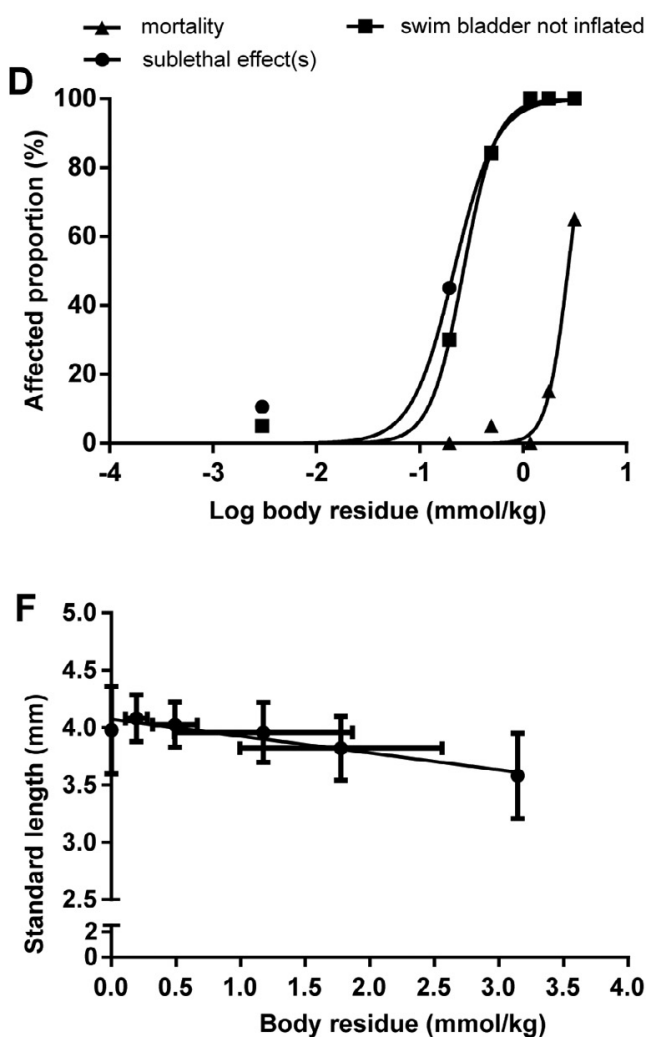

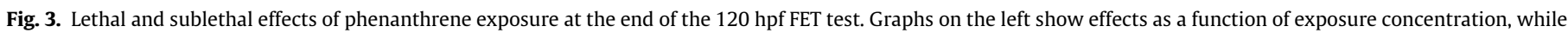

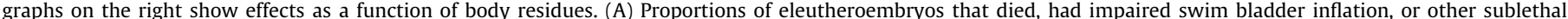

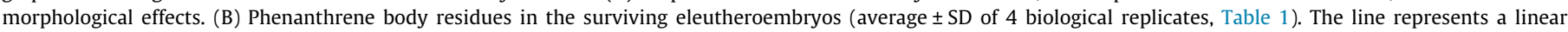

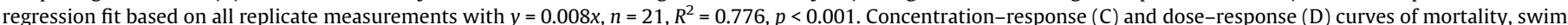

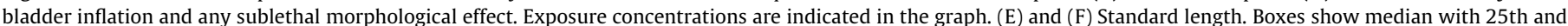

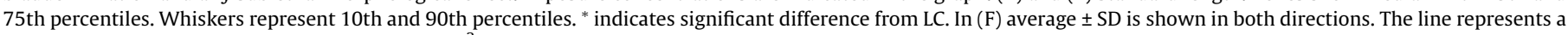
linear regression fit with $y=-0.15 x+4.07, n=6, R^{2}=0.908, p=0.003$.

effect concentrations necessary for ecological risk assessment. We have shown that controlled exposure concentrations facilitate determination of effect concentrations with narrow confidence intervals, and allow for obtaining mechanistic toxicity information.

\subsection{Requirement 3: The passive dosing format itself causes no toxicity}

There were no mortalities in the internal negative controls. At $120 \mathrm{hpf}$, mortality in the positive controls was $8 \%, 0 \%, 50 \%$ and $100 \%$ in $0.5 ; 1 ; 2$ and $4 \mathrm{mg} / \mathrm{L}$ DCA respectively, showing adequate sensitivity of the zebrafish embryos (OECD, 2013). We observed $0 \%$ mortality in C, $10 \%$ in RC, and $5 \%$ in LC, all within the limits set in OECD TG 236 (OECD, 2013), namely a survival of $\geqslant 90 \%$ in the controls. We did not observe any effects of RC or LC on measured endpoints (Figs. 3 and 4), except for the activity pattern of RC (Fig. 4C), but this does not show a consistent effect of the passive dosing format. Although the embryos are often in physical contact with the O-rings (visual observation), this had no effect on the endpoints that were assessed. Therefore, we conclude that the silicone $\mathrm{O}$-rings provide for a safe format for exposing zebrafish embryos to hydrophobic compounds.

\subsection{Conclusion}

We showed that the use of silicone O-rings for controlled exposure of zebrafish embryos to phenanthrene met the formulated 
Table 2

Characteristics of concentration- and dose-response curves at the end of the 120 hpf FET test.

\begin{tabular}{|c|c|c|c|}
\hline & $\begin{array}{l}\text { As a function of exposure } \\
\text { concentration }(\mu \mathrm{g} / \mathrm{L})\end{array}$ & $\begin{array}{l}\text { As a function of accumulated } \\
\text { dose (ng/embryo) }\end{array}$ & $\begin{array}{l}\text { As a function of body } \\
\text { residue (mmol } / \mathrm{kg} \text { fresh } \mathrm{wt})\end{array}$ \\
\hline Mortality & $\begin{array}{l}\mathrm{LC}_{50}: 310.0 \\
\mathrm{CI}_{95}: 272.3-352.9 \\
\text { Slope: } 5.94 \\
R^{2}: 0.977\end{array}$ & $\begin{array}{l}\text { LD }_{50}: 170.8 \\
\text { CI }_{95}: 160.8-181.4 \\
\text { Slope: } 6.35 \\
R^{2}: 0.984\end{array}$ & $\begin{array}{l}\mathrm{CBR}_{50}: 2.72 \\
\mathrm{CI}_{95}: 2.47-2.99 \\
\text { Slope: } 4.27 \\
R^{2}: 0.982\end{array}$ \\
\hline Impaired swim bladder inflation & $\begin{array}{l}\mathrm{EC}_{50}: 59.3 \\
\mathrm{Cl}_{95}: 55.5-63.4 \\
\text { Slope: } 4.45 \\
R^{2}: 0.997\end{array}$ & $\begin{array}{l}\mathrm{ED}_{50}: 20.2 \\
\mathrm{CI}_{95}: 18-22.6 \\
\text { Slope: } 2.71 \\
R^{2}: 0.997\end{array}$ & $\begin{array}{l}\mathrm{EBR}_{50}: 0.27 \\
\mathrm{CI}_{95}: 0.24-0.30 \\
\text { Slope: } 2.75 \\
R^{2}: 0.997\end{array}$ \\
\hline Any sublethal morphological effect & $\begin{array}{l}\mathrm{EC}_{50}: 52.1 \\
\mathrm{Cl}_{95}: 44.3-61.4 \\
\text { Slope: } 3.44 \\
\mathrm{R}^{2}: 0.983\end{array}$ & $\begin{array}{l}\mathrm{ED}_{50}: 16.3 \\
\mathrm{Cl}_{95}: 12.4-21.4 \\
\text { Slope: } 2.12 \\
\mathrm{R}^{2}: 0.982\end{array}$ & $\begin{array}{l}\mathrm{EBR}_{50}: 0.21 \\
\mathrm{Cl}_{95}: 0.16-0.28 \\
\text { Slope: } 2.13 \\
\mathrm{R}^{2}: 0.983\end{array}$ \\
\hline
\end{tabular}

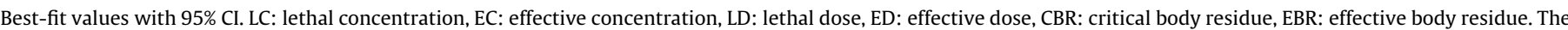
ratio between lethal and effective concentrations can inform on the specificity of sublethal effects. For a more detailed discussion of these ratios, see Appendix.

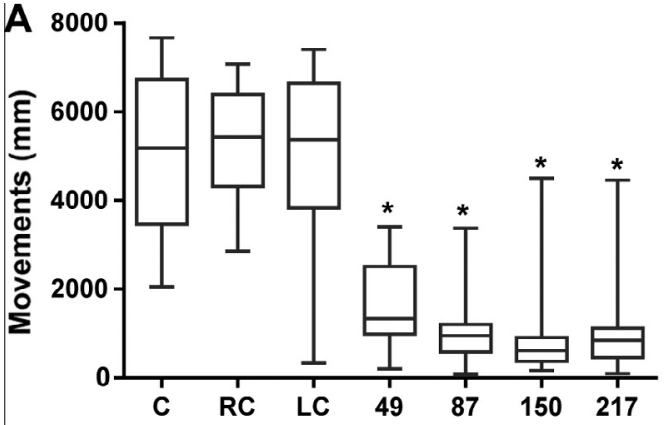

Phenanthrene exposure concentration $(\mu \mathrm{g} / \mathrm{L})$

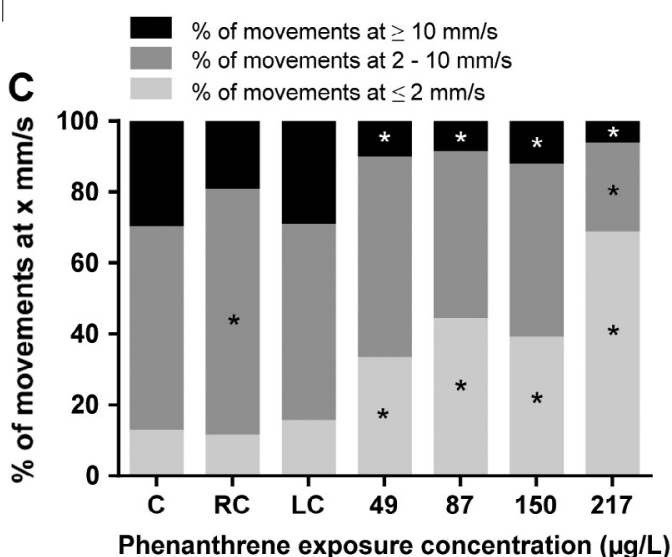

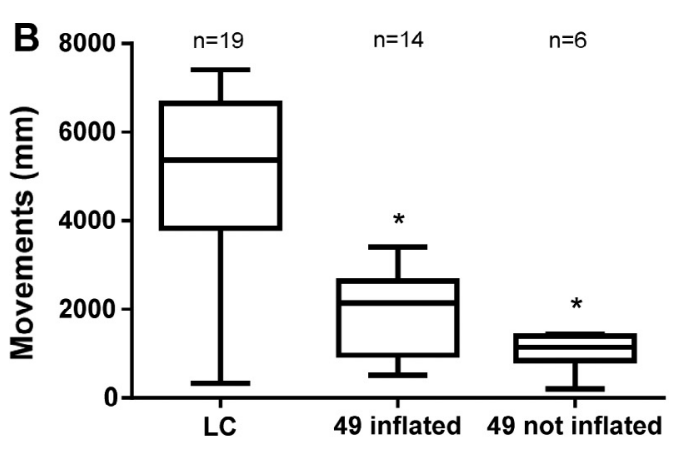

Phenanthrene exposure concentration ( $\mu \mathrm{g} / \mathrm{L})$

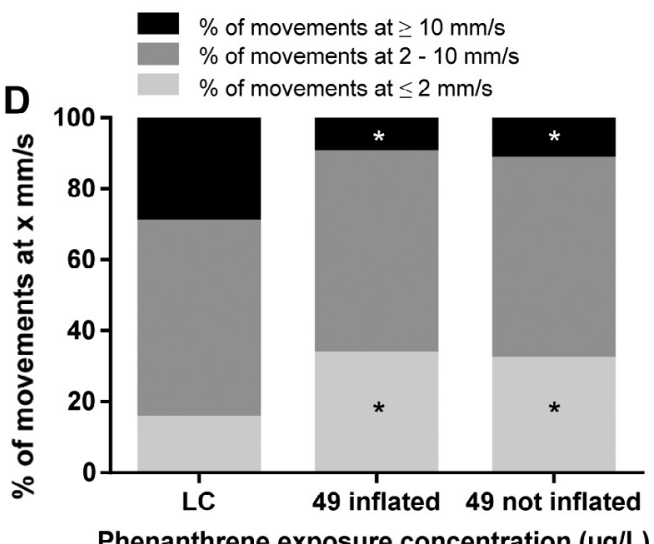

Phenanthrene exposure concentration ( $\mu \mathrm{g} / \mathrm{L})$

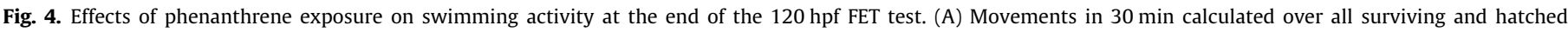

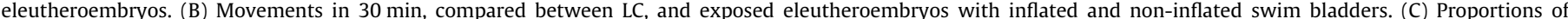

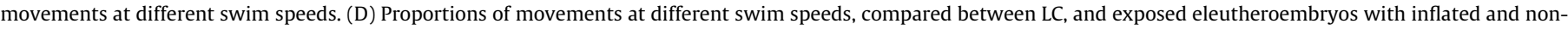
inflated swim bladders. Boxes show median with 25 th and 75 th percentiles. Whiskers represent 10 th and 90 th percentiles. ${ }^{*}$ indicates significant difference from LC.

requirements. Together with the practical advantages, this shows the potential of the format as an extension of the FET test, specifically when testing hydrophobic chemicals. Additional studies should test this passive dosing format with different chemicals, both solids and liquids, in order to assess its applicability in terms of the $\log K_{\text {ow }}$ range and/or any other chemical characteristics.

\section{Acknowledgements}

This work was funded by the Cefic Long-range Research Initiative (http://www.cefic-lri.org/) (LRI-ECO20) with support of
ECETOC, and a BOF-LP Project (2011-2015) of the University of Antwerp. We acknowledge additional support from LRI-ECO16. Lucia Vergauwen was supported by the LRI-ECO20 project.

\section{Appendix A. Supplementary material}

Supplementary data associated with this article can be found, in the online version, at http://dx.doi.org/10.1016/j.chemosphere. 2015.05.041. 


\section{References}

Bagci, E., Heijlen, M., Vergauwen, L., Hagenaars, A., Houbrechts, A.M., Esguerra, C.V., Blust, R., Darras, V.M., Knapen, D., 2015. Deiodinase knockdown during early zebrafish development affects growth, development, energy metabolism, motility and phototransduction. PLoS ONE 10, e0123285.

Barata, C., Calbet, A., Saiz, E., Ortiz, L., Bayona, J.M., 2005. Predicting single and mixture toxicity of petrogenic polycyclic aromatic hydrocarbons to the copepod Oithona davisae. Environ. Toxicol. Chem. 24, 2992-2999.

Belanger, S.E., Rawlings, J.M., Carr, G.J., 2013. Use of fish embryo toxicity tests for the prediction of acute fish toxicity to chemicals. Environ. Toxicol. Chem. 32, 17681783.

Billiard, S.M., Timme-Laragy, A.R., Wassenberg, D.M., Cockman, C., Di Giulio, R.T. 2006. The role of the aryl hydrocarbon receptor pathway in mediating synergistic developmental toxicity of polycyclic aromatic hydrocarbons to zebrafish. Toxicol. Sci. 92, 526-536.

Busquet, F., Strecker, R., Rawlings, J.M., Belanger, S.E., Braunbeck, T., Carr, G.J., Cenijn, P., Fochtman, P., Gourmelon, A., Huebler, N., Kleensang, A., Knoebel, M., Kussatz, C., Legler, J., Lillicrap, A., Martinez-Jeronimo, F., Polleichtner, C., Rzodeczko, H., Salinas, E., Schneider, K.E., Scholz, S., van den Brandhof, E.-J., van der Ven, L.T.M., Walter-Rohde, S., Weigt, S., Witters, H., Haider, M., 2014. OECD validation study to assess intra- and inter-laboratory reproducibility of the zebrafish embryo toxicity test for acute aquatic toxicity testing. Regul. Toxicol. Pharm. 69, 496-511.

Butler, J.D., Parkerton, T.F., Letinski, D.J., Bragin, G.E., Lampi, M.A., Cooper, K.R., 2013. A novel passive dosing system for determining the toxicity of phenanthrene to early life stages of zebrafish. Sci. Total Environ. 463, 952-958.

Call, D.J., Brooke, L.T., Harting, S.L., Poirier, S.H., McCauley, D.J., 1986. Toxicity of Phenanthrene to Several Freshwater Species. University of Wisconsin-Superior, Center for Lake Superior Environmental Studies, Superior, WI.

Di Toro, D.M., McGrath, J.A., Hansen, D.J., 2000. Technical basis for narcotic chemicals and polycyclic aromatic hydrocarbon criteria. I. Water and tissue. Environ. Toxicol. Chem. 19, 1951-1970.

EU Commission Implementing Decision 2012/707/EU of 14 November 2012 establishing a common format for the submission of the information pursuant to Directive 2010/63/EU of the European Parliament and of the Council on the protection of animals used for scientific purposes.

EU Parliament and Council Directive 2010/63/EU of 22 September 2010 on the protection of animals used for scientific purposes.

Hagenaars, A., Stinckens, E., Vergauwen, L., Bervoets, L., Knapen, D., 2014. PFOS affects posterior swim bladder chamber inflation and swimming performance of zebrafish larvae. Aquat. Toxicol. 157, 225-235.

Hawkins, S.A., Billiard, S.M., Tabash, S.P., Brown, R.S., Hodson, P.V., 2002. Altering cytochrome p4501a activity affects polycyclic aromatic hydrocarbon metabolism and toxicity in rainbow trout (Oncorhynchus mykiss). Environ. Toxicol. Chem. 21, 1845-1853.

Incardona, J.P., Collier, T.K., Scholz, N.L., 2004. Defects in cardiac function precede morphological abnormalities in fish embryos exposed to polycyclic aromatic hydrocarbons. Toxicol. Appl. Pharm. 196, 191-205.

Incardona, J.P., Carls, M.G., Teraoka, H., Sloan, C.A., Collier, T.K., Scholz, N.L., 2005. Aryl hydrocarbon receptor-independent toxicity of weathered crude oil during fish development. Environ. Health Perspect. 113, 1755-1762.

Knapen, D., Vergauwen, L., Villeneuve, D.L., Ankley, G.T., 2015. The potential of AOP networks for reproductive and developmental toxicity assay development Reprod. Toxicol. http://dx.doi.org/10.1016/j.reprotox.2015.04.003.

Kramer, N.I., Busser, F.J.M., Oosterwijk, M.T.T., Schirmer, K., Escher, B.I., Hermens, J.L.M., 2010. Development of a partition-controlled dosing system for cell assays. Chem. Res. Toxicol. 23, 1806-1814.

Lammer, E., Carr, G.J., Wendler, K., Rawlings, J.M., Belanger, S.E., Braunbeck, T., 2009 Is the fish embryo toxicity test (FET) with the zebrafish (Danio rerio) a potential alternative for the fish acute toxicity test? Comp. Biochem. Phys. C 149, 196209.

Lanham, K.A., Plavicki, J., Peterson, R.E., Heideman, W., 2014. Cardiac myocytespecific AHR activation phenocopies TCDD-induced toxicity in zebrafish. Toxicol. Sci. 141, 141-154.

Mackay, D., McCarty, L.S., Arnot, J.A., 2014. Relationships between exposure and dose in aquatic toxicity tests for organic chemicals. Environ. Toxicol. Chem. 33, 2038-2046.

Mayer, P., Reichenberg, F., 2006. Can highly hydrophobic organic substances cause aquatic baseline toxicity and can they contribute to mixture toxicity? Environ. Toxicol. Chem. 25, 2639-2644.
Mayer, P., Wernsing, J., Tolls, J., de Maagd, P.G.J., Sijm, D., 1999. Establishing and controlling dissolved concentrations of hydrophobic organics by partitioning from a solid phase. Environ. Sci. Technol. 33, 2284-2290.

McCarty, L.S., Arnot, J.A., Mackay, D., 2013. Evaluation of critical body residue data for acute narcosis in aquatic organisms. Environ. Toxicol. Chem. 32, 2301-2314.

McGrath, J.A., Di Toro, D.M., 2009. Validation of the target lipid model for toxicity assessment of residual petroleum constituents: monocyclic and polycyclic aromatic hydrocarbons. Environ. Toxicol. Chem. 28, 1130-1148.

McKim, J.M., Bradbury, S.P., Niemi, G.J., 1987. Fish acute toxicity syndromes and their use in the QSAR approach to hazard assessment. Environ. Health Perspect. $71,171-186$.

OECD, 1992. OECD guidelines for the testing of chemicals. Fish, Acute Toxicity Test, no. 203.

OECD, 2011. Validation report (phase 1 ) for the zebrafish embryo toxicity test. Part 1 \& 2. OECD Series on Testing and Assessment, no. 157.

OECD, 2012a. Annexes to the validation report (phase 2) for the zebrafish embryo toxicity test. Series on Testing and Assessment, no. 179.

OECD, 2012b. Fish toxicity testing framework. Series on Testing and Assessment, no. 171.

OECD, 2013. OECD guidelines for the testing of chemicals. Fish Embryo Acute Toxicity (FET) Test, no.236.

Petersen, G., 1997. Comparative Studies of Toxic Effects and Bioaccumulation of Lipophilic Organic Substances in Fish Early Life Stages (PhD).

Petersen, G.I., Kristensen, P., 1998. Bioaccumulation of lipophilic substances in fish early life stages. Environ. Toxicol. Chem. 17, 1385-1395.

Reichenberg, F., Mayer, P., 2006. Two complementary sides of bioavailability: accessibility and chemical activity of organic contaminants in sediments and soils. Environ. Toxicol. Chem. 25, 1239-1245.

Riedl, J., Altenburger, R., 2007. Physicochemical substance properties as indicators for unreliable exposure in microplate-based bioassays. Chemosphere 67, 2210-2220.

Rowe, C.L., Hopkins, W.a., Zehnder, C., Congdon, J.D., 2001. Metabolic costs incurred by crayfish (Procambarus acutus) in a trace element-polluted habitat: further evidence of similar responses among diverse taxonomic groups. Comp. Biochem. Physiol. C 129, 275-283.

Schmidt, S.N., Mayer, P., 2015. Linking algal growth inhibition to chemical activity: baseline toxicity required $1 \%$ of saturation. Chemosphere 120, 305-308.

Schreiber, R., Altenburger, R., Paschke, A., Kuester, E., 2008. How to deal with lipophilic and volatile organic substances in microtiter plate assays. Environ. Toxicol. Chem. 27, 1676-1682.

Seiler, T.-B., Best, N., Fernqvist, M.M., Hercht, H., Smith, K.E.C., Braunbeck, T., Mayer, P., Hollert, H., 2014. PAH toxicity at aqueous solubility in the fish embryo test with Danio rerio using passive dosing. Chemosphere 112, 77-84.

Smith, K.E.C., Dom, N., Blust, R., Mayer, P., 2010a. Controlling and maintaining exposure of hydrophobic organic compounds in aquatic toxicity tests by passive dosing. Aquat. Toxicol. 98, 15-24.

Smith, K.E.C., Oostingh, G.J., Mayer, P., 2010b. Passive dosing for producing defined and constant exposure of hydrophobic organic compounds during in vitro toxicity tests. Chem. Res. Toxicol. 23, 55-65.

Straehle, U., Scholz, S., Geisler, R., Greiner, P., Hollert, H., Rastegar, S., Schumacher, A., Selderslaghs, I., Weiss, C., Witters, H., Braunbeck, T., 2012. Zebrafish embryos as an alternative to animal experiments - a commentary on the definition of the onset of protected life stages in animal welfare regulations. Reprod. Toxicol. 33, $128-132$.

van der Heijden, S.A., Hermens, J.L.M., Sinnige, T.L., Mayer, P., Gilbert, D., Jonker, M.T.O., 2015. Determining high-quality critical body residues for multiple species and chemicals by applying improved experimental design and data interpretation concepts. Environ. Sci. Technol. 49, 1879-1887.

Van Wezel, A.P., Opperhuizen, A., 1995. Narcosis due to environmental pollutants in aquatic organisms - residue-based toxicity, mechanisms, and membrane burdens. Crit. Rev. Toxicol. 25, 255-279.

Vergauwen, L., Knapen, D., Hagenaars, A., De Boeck, G., Blust, R., 2013. Assessing the impact of thermal acclimation on physiological condition in the zebrafish model. J. Comp. Physiol. B. 183, 109-121.

Villeneuve, D., Volz, D.C., Embry, M.R., Ankley, G.T., Belanger, S.E., Leonard, M., Schirmer, K., Tanguay, R., Truong, L., Wehmas, L., 2014. Investigating alternatives to the fish early-life stage test: a strategy for discovering and annotating adverse outcome pathways for early fish development. Environ. Toxicol. Chem. 33, 158-169.

Wang, H.L., Che, B.G., Duan, A.L., Mao, J.W., Dahlgren, R.A., Zhang, M.H., Zhang, H.Q. Zeng, A.B., Wang, X.D., 2014. Toxicity evaluation of beta-diketone antibiotics on the development of embryo-larval zebrafish (Danio rerio). Environ. Toxicol. 29, 1134-1146. 